\title{
Utilidad del estudio de las heces para el diagnóstico y manejo de lactantes y prescolares con diarrea aguda
}

Alfredo Larrosa-Haro, MC, ${ }^{(1)}$ Marcia Ruiz-Pérez, MC, ${ }^{(1)}$ Sergio A guilar-Benavides, MC, M en C.. ${ }^{(2)}$

\begin{abstract}
Larrosa-Haro A, Ruiz-Pérez M,Aguilar-Benavides S. Utilidad del estudio de las heces para el diagnóstico y tratamiento de lactantes y prescolares con diarrea aguda.

Salud Publica Mex 2002;44:328-334. El texto completo en inglés de este artículo está disponible en: http://www.insp.mx/salud/index.html
\end{abstract}

\section{Resumen}

Objetivo. Analizar los resultados de un protocolo de estudio de las heces en una serie de lactantes y prescolares con diarrea aguda. Material y métodos Estudio transversal descriptivo efectuado entre abril de 1999 y marzo de 2000 en una muestra de 288 prescolares y lactantes, atendidos en un consultorio pediátrico no institucional de la ciudad de Guadalajara, México. La edad promedio fue de $23.1 \pm 13.9$ meses. El $43 \%$ fueron niñas. Se tomaron datos generales sociodemográficos y clínicos. Las heces se estudiaron con frotis en fresco, tinciones de azul de metileno y Kinyoun. Se analizaron pH y sustancias reductoras. Se hizo coprocultivo en casos con $\geq 3$ leucocitos/campo y el antígeno de rotavirus se midió en casos seleccionados. Se empleó estadística descriptiva, $\chi^{2}$, RM e intervalo de confianza de $95 \%$. Resultados A gentes identificados (\% del total de muestras estudiadas): Rotavirus 47.1, Campylobacter jejuni 27.4, Salmonella spp. 5.1, Shigella spp. 4.3, Cryptosporidium parvum 2.8, Giardia lamblia 2.4, Blastocystis hominis 1.4, Entamoeba histolytica 0.7. La RM para aislamiento de bacterias enteropatógenas en presencia de leucocitos fue de 5.7. Intolerancia a la lactosa en $19.1 \%$ de la muestra. La frecuencia de rotavirus e intoler ancia a la lactosa fue mayor en lactantes; la RM para intolerancia a la lactosa en casos con rotavirus fue de 21. La presencia de moco y sangre se asoció con agentes bacterianos y con Cryptosporidium parvum. Conclusiones Con el protocolo aplicado fue posible identificar en forma inmediata agentes parasitarios, rotavirus e intoleran-

\author{
Larrosa-Haro A, Ruiz-Pérez M,Aguilar-Benavides S. \\ Stool work-up protocol in infants \\ and preschool children with acute diarrhea: \\ Is it useful for diagnosis and treatment? \\ Salud Publica Mex 2002;44:328-334. \\ The English version of this paper \\ is available at: http://www.insp.mx/salud/index.html
}

\begin{abstract}
A bstract
ObjectiveTo analyze the results of a stool work-up protocol in a series of infants and preschoolers with acute diarrhea. Material and MethodsA cross-sectional descriptive study was conducted between April 1999 and March 2000, among 288 children seen at a pediatric office in Guadalajara, Mexico. The mean age ( $\pm 1 S D$ ) was $23.1 \pm 13.9$ months; $43 \%$ were females. Data were collected on demographic and clinical characteristics. The stool work-up consisted of fresh smear and methylene blue and Kinyoun smears, as well as determination of $\mathrm{pH}$ and reducing substances. Stool culture was performed in samples with $\geq 3$ leukocytes/microscopic field and rotavirus antigen detection only in selected cases. $D$ ata were analyzed using descriptive statistics, $\chi^{2}$, odds ratios, and $95 \%$ confidence intervals. Results Enterophatogens (\%) identified were: rotavirus 47.1, Campylobacter jejuni 27.4, Salmonella spp. 5.1, Shigella spp. 4.3, Cryptosporidium parvum 2.8, Giardia lamblia 2.4, Blastocystis hominis 1.4, Entamoeba histolytica 0.7. An OR of 5.7 was obtained for isolation of enteroinvasive bacteria in the presence of fecal leukocytes. Lactose intolerance was detected in $19.1 \%$. The frequencies of rotavirus antigen identification and lactose intolerance were significantly higher in infants; the OR for lactose intolerance in infants with rotavirus was 21. Mucus and blood in the stools were asso ciated to entero invasive bacteria and Cryptosporidium parvum. Conclusions The current stool work-up protocol allowed the identification of enteropathogenic parasites, rotavirus and lactose intolerance in a short period of time.
\end{abstract}

(1) Unidad de Investigación Médica en Epidemiología Clínica. Centro Médico N acional de 0 ccidente. Instituto Mexicano del Seguro Social (IMSS). Guadalajara, Jalisco, México.

(2) Laboratorio Regional de Referencia Epidemiológica, IMSS, Guadalajara, Jalisco, México.

Fecha de recibido: 31 de julio de 2001 - Fecha de aprobado: 11 de febrero de 2002

Solicitud de sobretiros:Alfredo Larrosa-Haro. Francisco Martínez de laVega 553, Lomas de Guadalupe. 45030 Zapopan, Jalisco, México. Correo electrónico: larrosa@ prodigy.net.mx 
cia a hidratos de carbono. La presencia de leucocitos en las heces se aso ció con el aislamiento de bacterias enteroinvasoras. La frecuencia de agentes patógenos identificados fue similar a la de otras series nacio nales. Este algoritmo puede limitar la prescripción de fármacos y la manipulación dietética exclusivamente a las indicaciones universalmente aceptadas. El texto completo en inglés de este artículo está disponible en: http://www.insp.mx/salud/index.html

Palabras clave: diarrea aguda; enterobacteriaceae; rotavirus; intolerancia a la lactosa; México
Leukocytes in stools were associated to the isolation of enteroinvasive bacteria. The frequency of agents associated to diarrheal disease was similar to that from other national studies.This stool work-up protocol could be useful as a tool to limit the unnecessary prescription of drugs and to follow universal recommendations for dietary management of these patients.The English version of this paper is available at:http:/ /www.insp.mx/salud/index.html

Key words: acute diarrhea; enterobacteriaceae; rotavirus; lactose intolerance; Mexico
$\mathrm{L}$ a enfermedad diarreica es un síndrome de etiología multicausal en la que el evento primario suele ser la interacción del organismo con agentes infecciosos virales, bacterianos y parasitarios, ${ }^{1-7}$ los eventos secundarios corresponden a las consecuencias del daño producido por estos agentes al organismo, particularmente al epitelio digestivo, en forma de pérdidas anormales de agua y sales, en la alteración en la digestión y absorción de nutrimentos (como la intolerancia a la lactosa) y, secundariamente, en la afectación del estado nutricio y el desarrollo de alergia alimentaria. ${ }^{8-10}$ Los mecanismos de acción de los agentes infecciosos asociados con la enfermedad diarreica son muy diversos, ya que mientras los virus no suelen inducir respuesta inflamatoria, en las infecciones por bacterias enteroinvasoras pueden presentarse evacuaciones con moco y sangre, además de leucocitos en las heces. ${ }^{2-4,6}$

En contraste con la disminución en la mortalidad asociada con enfermedad diarreica en México en la última década, ${ }^{11-14}$ su prevalencia se ha mantenido estable e incluso muestra una tendencia ascendente hacia el final de la década de los noventa, ${ }^{11,12}$ por lo que es evidente que este problema de salud sigue siendo un motivo de consulta frecuente y cotidiano en el primer nivel de atención.

Los propósitos de este trabajo fueron describir los resultados del estudio de una muestra de heces fecales, en una serie de lactantes y prescolares con diarrea aguda, atendidos en un consultorio no institucional de primer contacto, en la ciudad de Guadalajara, México, y discutir sobre la posible utilidad de este abordaje en el diagnóstico y tratamiento de lactantes y prescolares con este síndrome.

\section{Material y métodos}

De abril de 1999 a marzo de 2000 se estudiaron consecutivamente 288 pacientes con diarrea aguda (heces flojas o acuosas, con una frecuencia de tres evacuaciones o más en relación con su hábito defecatorio de 24 horas y con una evolución menor a 14 días) en un consultorio pediátrico no institucional de la ciudad de Guadalajara. Se excluyeron pacientes con diarrea de más de 14 días de evolución, pacientes con diarrea recurrente y casos que habían recibido tratamiento con antibióticos o antiparasitarios en el curso de su enfermedad actual.

Se recabaron datos generales (nombre, fecha de nacimiento, edad y género), algunos datos sociodemográficos (escolaridad y ocupación de los padres, número de hijos de la familia) y datos clínicos que incluyeron tiempo de evolución de la diarrea, manifestaciones de deshidratación (mucosa oral seca, ojos hundidos, fontanela anterior deprimida, signo del lienzo húmedo), fiebre, vómito y características de las evacuaciones, así como la presencia de moco y sangre. Durante la exploración física se buscaron en forma intencionada datos de deshidratación.

En todos los casos se hizo medición de peso (a los lactantes en báscula pesa-bebé Health-meter, con una lectura mínima de $10 \mathrm{~g}$, y a los prescolares en una báscula de brazo Health-meter, con una lectura mínima de 100g; con pañal los primeros y en ropa interior los segundos, previa calibración del instrumento). La longitud en los lactantes se midió en decúbito con un infantómetro, y la talla de los prescolares se midió de pie, por medio de un estadiómetro, de acuerdo con técnicas antropométricas establecidas. ${ }^{15}$ Con los datos antropométricos se calcularon los índices talla/edad y peso/talla del porcentaje de la mediana, se utilizó el patrón de referencia del National Center for Heath and Statistics ${ }^{16}$ y se clasificó el estado de nutrición conforme a los criterios de Waterlow. ${ }^{17}$

En las siguientes 48 horas de su valoración clínica inicial a todos los pacientes se les hizo estudio de heces recientes (evacuación de menos de una hora de emitida, colectada en un recipiente de plástico $u$ ob- 
tenida en el laboratorio por estimulación rectal) que consistió en: a) preparación en fresco con solución salina al $0.9 \%$ (objetivo 40x) para búsqueda de trofozoitos, eritrocitos, levaduras, quistes, larvas y huevecillos de parásitos; b) tinción con azul de metileno para búsqueda y conteo de leucocitos (objetivo 100x); c) tinción de Kinyoun para identificación de coccidias; d) pH (medición semicuantitativa, Neutralit ${ }^{\circledR}$ pH 5-10 Merck) y sustancias reductoras (Clinitest ${ }^{\circledR}$, Bayer Diagnostics); e) coprocultivo en las muestras en las que se identificaron tres o más leucocitos por campo microscópico (100x); los medios de cultivo empleados fueron agar EMB, agar de Mac Conkey con sorbitol, agarXLD, agar SS y medios de enriquecimiento para Vibrio cholerae y Salmonella spp.; agua peptonada y caldo selenito, respectivamente, con resiembra el primero en agar TCBS y en agar XLD el segundo; $\mathrm{f}$ ) el aislamiento de Campylobacter spp. se realizó en el medio de CampyBAP, el cual se incubó en una estufa con $\mathrm{CO}_{2}$ a $10 \%$ y a $42{ }^{\circ} \mathrm{C}$ durante 72 horas; la identificación se realizó con las pruebas de oxidasa, catalasa, hidrólisis de hipurato, producción de $\mathrm{H}_{2} \mathrm{~S}$ en TSI, y susceptibilidad a cefalotina y ácido nalidíxico $(30 \mu \mathrm{g}), \mathrm{y}$ g) rotavirus en heces por el método de coaglutinación en placa (Biomerieux $\left.{ }^{\circledR}\right)$ durante los meses de noviembre de 1999 a febrero de $2000 \cdot{ }^{18-20}$ No se hicieron pruebas para la identificación de Escherichia coli enterotoxigénica, enteroinvasiva o enteropatógena. Con un criterio aleatorio, en 46 casos, con tinción de azul de metileno negativa a leucocitos, se realizó coprocultivo.

El análisis estadístico de los datos se efectuó a través de estadística descriptiva y $\chi^{2}$ o prueba exacta de Fisher para la comparación de frecuencias de variables cualitativas nominales, $R M$ e intervalo de confianza de 95\% (IC 95\%).

El protocolo fue revisado y aprobado por el Comité de Investigación del Hospital de Pediatría (99-251-025). Se solicitó autorización verbal a los padres para incluir a sus hijos en el presente estudio.

\section{Resultados}

La edad promedio de los 288 pacientes estudiados fue de $23.1 \pm 13.9$ meses $( \pm 1 D E)$; $132(45.8 \%)$ casos se ubicaron en el grupo etáreo de lactantes ( $<19$ meses de edad), y $156(54.2 \%)$ en el de prescolares (19 meses a cinco años). El 57.3\%, 165, fueron del sexo masculino.

Características sociodemográficas: a) escolaridad. De 576 padres, $259(44.9 \%)$ se clasificaron en nivel profesional, 108 (18.8\%) profesional inconcluso, 202 $(35.1 \%)$ preparatoria y $7(1.2 \%)$ preparatoria inconclusa; b) ocupación: 137 (36.7\%) eran empleados, 132 (35.3\%) comerciantes independientes y $105(28.1 \%)$ profesionales independientes; en 86 matrimonios (29.9\%) trabajaban ambos padres, y c) promedio de número de hijos por familia: $2.17 \pm 0.65( \pm 1 D E)$.

Al momento del estudio de las heces, el tiempo de evolución de la diarrea fue de $41 \pm 8( \pm 1 D E)$ horas. Se documentó fiebre en 184 (63.9\%), vómito en 167 (57.9\%); las heces mostraron moco en $160(55.6 \%)$ y moco con sangre en $63(21.9 \%)$ casos. Todos los pacientes fueron manejados inicialmente con los planes A o B de hidratación oral; 7 en ningún caso se documentó deshidratación durante la evolución de la enfermedad ni se requirió de hospitalización. Los pacientes fueron valorados clínicamente, cuando menos en una ocasión, en los siguientes seis meses a su episodio diarreico; tres de los 288 casos tuvieron una evolución mayor a 14 días, por lo que se consideraron como diarrea persistente; estos tres casos habían tenido leucocitos en las heces y en ellos se aisló Salmonella spp. en el coprocultivo.

El porcentaje de la mediana del índice talla para la edad se ubicó entre 95 y 105\% en 285 casos, lo que de acuerdo con la Clasificación de Waterlow corresponde a una longitud o estatura normal. ${ }^{17}$ En tres casos, este índice talla/edad fue $<90 \%$; en estos tres pacientes ya se contaba con un diagnóstico previo de desaceleración del crecimiento relacionado con cardiopatía congénita, prematurez y uropatía obstructiva con insuficiencia renal intermedia. El porcentaje de la mediana del índice peso para la talla se ubicó entre 90 y $100 \%$ en los 288 casos, lo que se consideró como estado actual de nutrición normal.

Los hallazgos de los frotis de heces en fresco y con la tinción de Kinyoun se presentan en el cuadro I. En 22 casos $(7.3 \%)$ se identificó a un agente parasitario de los considerados como enteropatógenos; el más frecuente fue Cryptosporidium parvum. En 86 casos (29.9\%), en la preparación en fresco, se observaron levaduras.

El conteo mostró en 28 casos de 1 a 10 leucocitos, en 16 de 11 a 20, en 10 de 21 a 30 y en 17 más de 30 leucocitos por campo microscópico. En 35 de estos 71 pacientes con leucocitos en heces se identificaron, además, eritrocitos. En todos los casos en los cuales se observaron leucocitos en las heces se realizó coprocultivo; la identificación de bacterias enteroinvasoras en este grupo de 71 niños con leucocitos positivos en la tinción de azul de metileno pudo realizarse en 36 de ellos (50.7\% del total de coprocultivos), siendo el aislamiento más frecuente el de Campylobacter jejuni; en los 46 casos con tinción de azul de metileno negativa a leucocitos en los cuales se efectuó coprocultivo, se aislaron bacterias enteroinvasoras en siete. No se encontró asociación estadística entre el número de leucocitos y los 


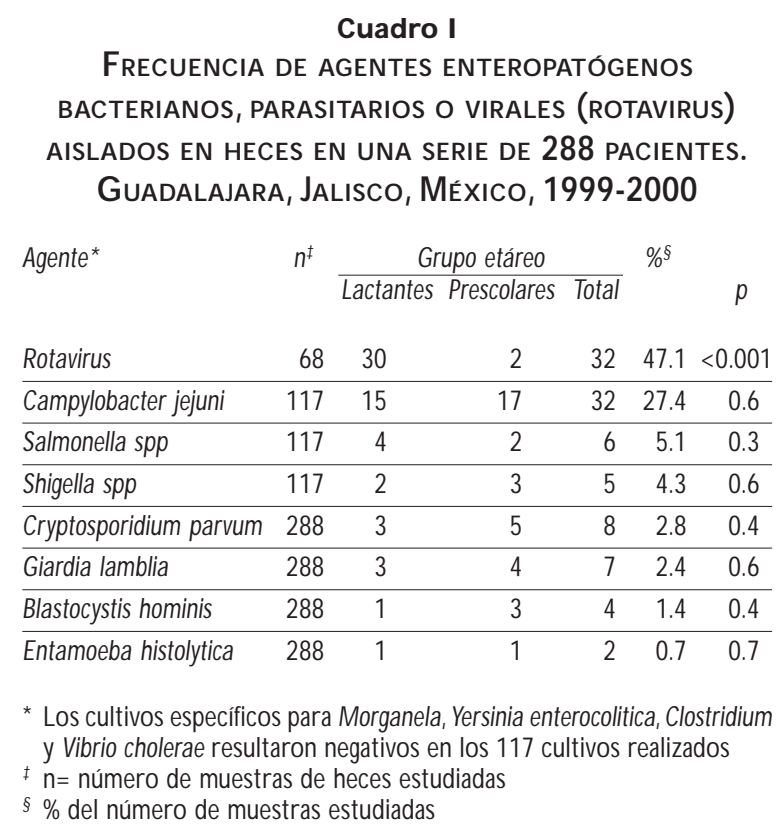

N ota: la comparación de las frecuencias se realizó con las pruebas $\chi^{2}$ y exacta de Fisher

agentes identificados. Las frecuencias de las bacterias enteropatógenas aisladas en estos 43 casos se presentan en el cuadro I.

La investigación del antígeno de rotavirus en las heces de 68 casos resultó positiva en 32 (47\% de las pruebas realizadas), lo que ubica a éste como el agente aislado en una proporción mayor (cuadro I). La distribución de frecuencias de identificación de rotavirus durante los meses de octubre de 1999 a marzo de 2000 muestra una mayor frecuencia durante los meses de diciembre y enero (figura 1 ).

La presencia de leucocitos en las heces y el aislamiento de una bacteria enteroinvasora en el coprocultivo mostraron una asociación significativa ( $R M$ de 5.7, IC 95\% 2.16 a 16.25) (cuadro II).

La comparación de las frecuencias de agentes enteropatógenos aislados en relación con los grupos de edad no mostró diferencias a excepción del de lactantes, en quienes la frecuencia de rotavirus fue significativamente mayor. La comparación intragrupal de características clínicas como la presencia de moco, sangre y vómito entre los casos asociados con agentes bacterianos o parasitarios no mostró diferencias $(p>0.05)$. La comparación intergrupal (agentes bacterianos, parasitarios y rotavirus) de estas características mostró que los casos asociados con agentes bacterianos tuvieron una mayor frecuencia de moco en las heces, al ser comparados con agentes pa-

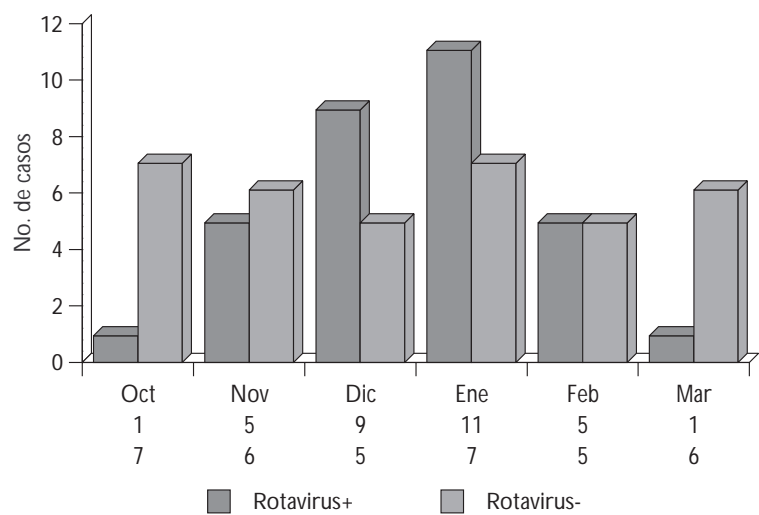

Figura 1. Frecuencia de antígeno de rotavirus (coAGLUTINACIÓN EN PLACA) EN LAS HECES DE 68 PACIENTES CON DIARREA AGUDA ESTUDIADOS DE OCTUBRE DE 1999 A marzo de 2000. Guadalajara, Jalisco, México

\section{Cuadro II \\ Comparativo de frecuencias de aislamiento DE BACTERIAS ENTEROPATÓGENAS* EN UNA SERIE DE NIÑOS CON DIARREA AGUdA. GUadalaJARA, Jalisco, México, 1999-2000}

\begin{tabular}{lccc} 
& Leucocitost & Leucocitos- & Total \\
Coprocultivo positivo & 36 & 37 & 43 \\
\hline Coprocultivo negativo & 35 & 39 & 74 \\
Total & 71 & 46 & 117 \\
$\begin{array}{l}\text { * Las bacterias enteropatógenas aisladas fueron Campylobacter jejuni, Sal- } \\
\text { monella spp. y Shigella spp. }\end{array}$ &
\end{tabular}

rasitarios y rotavirus $(p<0.001)$. En cuanto a la presencia de moco y sangre, no se encontró diferencia al comparar las frecuencias de bacterias enteropatógenas y parásitos $(p=0.41)$; sin embargo, al excluir a los casos con Cryptosporidium paroum -de los que más de la mitad tuvieron moco y sangre- esta diferencia se tornó significativa $(p=0.01)$. En los casos con bacterias enteroinvasoras la frecuencia de moco y sangre fue mayor que los casos con rotavirus ( $p=0.001$ ) (cuadro III).

La comparación de las frecuencias de los agentes enteropatógenos identificados con relación a las características sociodemográficas, escolaridad, ocupación y número de hijos, no mostró diferencias significativas $\left(\chi^{2}, p>0.05\right)$. La evolución mayor a dos 


\section{Cuadro III \\ Características clínicas en 96 pacientes pediátricos en quienes se identificó algún agente enteropatógeno bacteriano, parasitario o viral. Guadalajara, Jalisco, México, 1999-2000}

\begin{tabular}{|c|c|c|c|c|c|c|}
\hline Agente ent & patógeno & $n$ & Moco & M oco y sangre & Vómito & Fiebre \\
\hline Bacterias & Campylobacter jejuni & 32 & 25 & 11 & 17 & 13 \\
\hline & Salmonella spp & 6 & 5 & 4 & 2 & 3 \\
\hline & Shigella spp & 5 & 5 & 3 & 3 & 3 \\
\hline Parásitos & Cryptosporidium parvum & 8 & 6 & 5 & 3 & 4 \\
\hline & Giardia lamblia & 7 & 1 & 0 & 3 & 1 \\
\hline & Blastocystis hominis & 4 & 1 & 0 & 2 & 0 \\
\hline & Entamoeba histolytica & 2 & 0 & 0 & 1 & 0 \\
\hline Virus & Rotavirus & 32 & 5 & 1 & 31 & 17 \\
\hline Total (\%) & & 96 & $48(50)$ & $24(25)$ & $62(64.6)$ & $41(42.7)$ \\
\hline
\end{tabular}

semanas (diarrea persistente) ocurrió en tres de los 288 casos estudiados (1.04\%).

Todos los casos estudiados recibían fórmula láctea con lactosa o leche entera cuando se presentó el episodio diarreico. En 49 de los 288 casos se demostró en una ocasión un $\mathrm{pH}$ en las heces igual o menor a 5.5, asociado con el hallazgo de sustancias reductoras $(0.5$ a $2 \mathrm{~g} / \mathrm{dl}$ ); en ellos se estableció el diagnóstico de intolerancia transitoria a la lactosa. De 49 pacientes, 46 correspondieron al grupo de lactantes, con una edad promedio de 10.2 \pm 3.7 meses; la comparación de las frecuencias de intolerancia a la lactosa entre los grupos de lactantes y prescolares mostró una diferencia significativa ( $\chi^{2}$ con corrección de Yates, $\left.p<0.001\right)$. En el grupo de niños con rotavirus se encontró asociación con intolerancia a lactosa cuando fueron comparados con los casos con rotavirus negativo (RM 21, IC 95\% 4-136).

\section{Discusión}

Aunque la mortalidad asociada con enfermedad diarreica en lactantes y prescolares en México ha disminuido, de 20.9\% en 1987 a 5.9\% en 1997 en los primeros, y de $29.8 \%$ a $11.3 \%$ en el mismo periodo en los segundos, la diarrea se sigue ubicando dentro de las primeras cuatro causas de muerte en estos dos grupos de edad. ${ }^{11-14}$ La presente serie de pacientes pediátricos con enfermedad diarreica aguda tiene las siguientes características especiales: a) corresponde a una zona urbana poco estudiada en este aspecto, b) las familias estudiadas tenían un nivel educativo medio o superior y se pueden considerar con una situación económica desahogada, y c) los sujetos eran niños previamente sanos y sin desnutrición asociada. La diarrea como motivo de atención pediátrica en un consultorio no institucional correspondió a $17.4 \%$ del total de consultas, lo que indica que este problema de salud fue significativo entre las familias estudiadas. Llama la atención la distribución de la enfermedad diarreica por grupos etáreos, ya que en las encuestas nacionales predomina en lactantes en una razón de 3 o 4:1, ${ }^{11,12}$ y en la serie reportada la relación fue de 1:1.18 en favor de los prescolares; es interesante el hecho de que no se demostraron complicaciones como deshidratación, ni se requirió la hospitalización en ningún caso.

La comparación de la frecuencia de evolución a diarrea persistente, con la de una serie de niños con diarrea infecciosa en el medio rural, que fue de $4.4 \%$ en 4465 casos $^{21}$ mostró una frecuencia significativamente menor en la presente serie $(p=0.010)$.

El estudio de las heces permitió identificar en forma inmediata un agente parasitario en $7.3 \%$ de los casos estudiados, y si se adiciona la detección del antígeno de rotavirus, esta proporción de agentes enteropatógenos se incrementa a 54.4\%; además, en 17\% de casos estudiados la evaluación inicial de las heces permitió añadir el diagnóstico de intolerancia a la lactosa. Hacer coprocultivo en los casos en quienes se observaron leucocitos en las heces mostró una evidente asociación de su presencia con el aislamiento de las bacterias enteroinvasoras Campylobacter jejuni, Sal- 
monella spp. y Shigella spp.; esta asociación ya ha sido descrita $^{22,23}$ y apoya la ventaja de hacer coprocultivo cuando se demuestran leucocitos en las heces de niños con diarrea. El hallazgo de evacuaciones con moco y sangre y leucocitos en las heces de algunos niños en quienes se identificó Cryptosporidium paroum es interesante, ya que este parásito se suele localizar en el intestino delgado y sólo ocasionalmente en el colon, particularmente en asociación con pacientes inmunocomprometidos, a coinfección con Shigella y a colitis ulcerativa crónica inespecífica, ${ }^{2,4,6,24}$ lo que no ocurrió en ninguno de los casos de la presente serie.

La correlación de los datos clínicos con los agentes identificados en el estudio de heces mostró como asociación significativa una mayor frecuencia de rotavirus y de intolerancia a la lactosa en lactantes, así como la presencia de moco o de moco y sangre con bacterias enteroinvasoras y Cryptosporidium parvum. No se demostró asociación entre la presencia de agentes bacterianos o parasitarios y género, escolaridad y ocupación de los padres, número de hijos y síntomas como fiebre o vómito.

Aunque la serie estudiada tiene sesgos como que la selección de la muestra no la hace representativa de la población general y que se parte de situaciones específicas, como la investigación de rotavirus exclusivamente en las estaciones de otoño e invierno, la frecuencia de los agentes identificados es comparable con la de otras series en otras poblaciones y en otros momentos epidemiológicos del país. ${ }^{2-5,25-27}$ En un estudio realizado en la Ciudad de México en niños con diarrea aguda se demostró rotavirus en forma endémica durante los doce meses del año. ${ }^{3}$ En otro estudio desarrollado en niños con diarrea aguda, atendidos en el servicio de Urgencias del Hospital de Pediatría en Guadalajara, en 1986, los agentes identificados con mayor frecuencia también fueron rotavirus y Campylobacter jejuni. ${ }^{27}$

Dada la naturaleza autolimitada de la mayoría de los casos de diarrea infecciosa aguda, en la práctica clínica cotidiana no se suelen efectuar estudios de laboratorio en este tipo de pacientes, ya que se consideran poco útiles para su manejo, el cual se sustenta en la hidratación oral y en mantener una alimentación normal. ${ }^{7,28}$ Sin embargo, en la práctica institucional -y probablemente también en la no institucional- en nuestro país se manejan esquemas y algoritmos de estudio y particularmente de manejo, que suelen incluir la prescripción de fármacos antidiarreicos, antiparasitarios y antibióticos, una indicación excesiva de hidratación endovenosa, esquemas de restricción y modificación alimentaria poco justificados y proba- blemente una prescripción excesiva de fórmulas sin lactosa. ${ }^{29-34}$ En este contexto, la realización de un protocolo de evaluación diagnóstica de las heces en niños con diarrea aguda podría resultar una herramienta útil para limitar, más que para inducir, la prescripción de fármacos o de fórmulas especiales. De acuerdo con los resultados encontrados con el protocolo aplicado en la presente serie de niños con diarrea aguda, la indicación teórica de un manejo específico según los criterios aceptados se circunscribiría a cinco casos con shigelosis $(11.3 \%$ de las bacterias enteropatógenas identificadas y $4.7 \%$ del total de coprocultivos), siete casos con giardiasis y dos con amibiasis (2.4 y $0.7 \%$, respectivamente, del total de estudios en fresco de heces); en relación con el número total de muestras estudiadas, este grupo de agentes identificados correspondió a $4.8 \%$ de los casos, con una indicación específica de manejo con antibióticos o antiparasitarios. La indicación de una fórmula sin lactosa -si se considera al hallazgo de $\mathrm{pH}$ ácido y sustancias reductoras en las heces como indicador de intolerancia a la lactosa ${ }^{8,35}$ en la serie estudiada correspondió a $17 \%$ del total de muestras estudiadas; este evento de mala absorción transitoria de hidratos de carbono se presentó casi exclusivamente en el grupo de niños menores a 19 meses de edad, y tuvo una alta asociación con la identificación de antígeno de rotavirus en las heces, variables que se pueden considerar como factores de riesgo.

La identificación de leucocitos, de bacterias enteroinvasoras como Salmonella spp. y de parásitos como Cryptosporidium parvum, podría permitir elaborar un pronóstico de una evolución mayor de 1 a 2 semanas, y de establecer la probabilidad de recurrencias por la historia natural ya descrita en estas entidades, ${ }^{2,4,6,21,24,30,36}$ como ocurrió en tres casos de la serie reportada, en quienes se aisló Salmonella spp.

En la serie reportada se muestran los resultados de un protocolo de estudio de las heces dirigido a identificar agentes asociados con la enfermedad diarreica. El grupo estudiado fue urbano, de niños sin desnutrición y sanos previamente, y de familias con un nivel educativo medio y superior. Los agentes identificados y la frecuencia relativa de su identificación fueron similares a los de otras series estudiadas en México. La indicación de intervención farmacológica (antimicrobianos o antiparasitarios) o dietética (fórmulas sin lactosa) derivada de los resultados del protocolo aplicado y de acuerdo con los criterios terapéuticos vigentes sería, en estas condiciones, de 4.8 y $17 \%$, respectivamente, del total de niños estudiados. El estudio de las heces de lactantes y prescolares con diarrea aguda podría añadir a los pilares básicos de 
manejo, a saber, hidratación oral y alimentación normal, datos útiles para mejorar el enfoque diagnóstico y terapéutico de este problema.

\section{Agradecimientos}

Al doctor Pedro Coello-Ramírez, por la revisión crítica del presente manuscrito.

\section{Referencias}

1. Gutiérrez G, G uiscafré H, Bronfman M, Martínez C, Padilla G, Muñoz 0 . Estrategias para mejorar los patrones terapéuticos utilizados en diarrea aguda en unidades de atención médica primaria. I. Metodología y características de las unidades médicas de la población estudiada. Arch Invest Med Mex 1988;19:335-336.

2. 0 larte J. Etiología de las diarreas infecciosas: viejos y nuevos agentes. Bol Med Hosp Infant Mex 1992:49:143-150.

3. Evans D G, 0 larte J, D uPont HL, Evans DJ, G alindo E, Portnoy BL et al. Enteropathogens associated with pediatric diarrhea in Mexico City.J Pediatr 1977;91:65-68

4. Muñoz 0 , Torres J.A vances en los criterios diagnósticos y terapéuticos en diarrea aguda. Gac Med Mex 1992;128:573-580.

5. 0 larte J, Pérez GI. Campylobacter jejuni in children with diarrhea in Mexico City. Pediatr Infect D is 1983:2:18-20.

6. Casemore DP, Sands RL, C urry A. Cryptosporidium species: A "new" human pathogen. J C lin Pathol 1985;38:1321-1336.

7. World Health 0 rganization. The treatment of diarrhea, a manual for physicians and other senior health workers. Ginebra: World Health $0 \mathrm{r}$ ganization;1999:1-62.

8. Lifshitz F, Coello RP, G utiérrez TG, Coronado CMC. Carbohydrate intolerance in infants with diarrhea.J Pediatr 1971;79:760-767.

9. MoliaA, MoliaAM, Sarker SA, Khatoon M, Bahaman MM. Effects of acute diarrhea on absorption of macronutrients during disease and after recovery. En: Chen LC, Scrimshaw N S, ed. Diarrhea and malnutrition: Interactions, mechanisms and interventions. N ueva York: Plenium, 1983: 143-154. 10. Jonas A,Avigad S, D iver-H aber A, Katznelson D. D isturbed fat absorption following infectious gastroenteritis in children. J Pediatr 1979;95: 366-372.

11. Secretaría de Salubridad y Asistencia.A nuario Estadístico 1987. Dirección General de Epidemiología. México, D.F.: SSA, 1988.

12. Secretaría de Salubridad y A sistencia. Mortalidad 1997. Dirección General de Estadística e Informática. México, D.F.: SSA, 1997.

13. Mota HF. Disminución de la mortalidad por diarrea en niños. Bol Med Hosp Infant Mex 2000;57:32-40.

14. Secretaría de Salud Jalisco.Anuario Epidemiológico 1998. Guadalajara, Jalisco: Comisión Estatal de Vigilancia Epidemiológica, 1997:143.

15. Ramos-Galván R. Somatometría pediátrica. Estudio semilongitudinal en niños de la Ciudad de México.Arch Invest Med Mex 1975;6 (Supl):155. 16. N ational C enter for Health Statistics. G rowth curves for children birth18 years. W ashington, DC: N ational Center for Health Statistics, 1977; (Vital and Heath Statistics, Series 11: \# 165 [D HEW publication \# 781650]).
17. W aterlow JC. Classification and definition of protein calorie malnutrition. Br Med J 1972;3:566-569.

18. Gilligan PH, Janda JM, Karmali MA, Miller JM. Laboratory diagnosis of bacterial Diarrhea. W ashington, D.C.:ASM Press, 1992.

19. Murray PR, Baron EJ, Pfaller MA, Tenover FC, Yolken RH. Manual of clinical microbiology. $7^{\text {th }}$ ed.W ashington, D.C.:ASM Press, 1999.

20. Forbes BA, Sahm DF,W eissfeld AS. Bailey \& Scott's diagnostic microbiology. $10^{\text {th }}$ ed. Saint Louis (MO ): Mosby 1998.

21. Gutiérrez G, Martínez M, Guiscafré H, G ómez G, Peniche A, Muñoz 0 . Encuesta sobre el uso de antimicriobianos y de hidratación oral en la diarrea infecciosa aguda en el medio rural mexicano. Bol Med Hosp Infant Mex 1987;44:582-588.

22. Coello RP, Movrin M, Díaz BS. Estudio del moco fecal en niños con diarrea aguda o prolongada. Bol Med Hosp Infant Mex 1976;33:61-78.

23. Harris JC, Dupont HL, Hornick RB. Fecal leukocytes in diarrheal illness.Ann Intern Med 1972:76:697-703.

24. García-Valverde E, Chávez-Legaspi M, C oello-Ramírez P, González PJ, A guilar-Benavides $S$. Cryptosporidium sp. in 300 children with and without diarrea. Arch Invest Med Mex 1991;22:329-332.

25. Muñoz HO, C o ello RP, Serafín AF, O larte J, Pickering LY, D upont $H$ et al. Gastroenteritis infecciosa aguda. Etiología y su correlación con las manifestaciones clínicas y el moco fecal. Arch Invest Med Mex 1979;10: 135-145.

26. G uiscafré H, G onzález S, Parra R, Lemus H, Alvarez MT, G uiscafré JP et al. III. Etiología y cuadro clínico de los casos estudiados. Arch Invest Med Mex 1988;19:361-370.

27. Lara-Avila MT. Aislamiento de microorganismos enteropatógenos en niños con diarrea (tesis). Guadalajara, Jalisco: U niversidad de G uadalajara, 1986.

28. Mota HF, Pérez CA, Velásquez JL. Impacto del Servicio de Hidratación 0 ral sobre la hospitalización de niños con diarrea en un hospital de tercer nivel de atención. Bol Med Hosp Infant Mex 1987;44:260-264.

29. Bronfman M, G uiscafré H, C astro V, C astro R, G utiérrez G. II La medición de la desigualdad: una estrategia metodológica, análisis de las características socioeconómicas de la muestra. Arch Invest Med Mex 1988:19: 351-360.

30. Guiscafré H, G onzález S, Parra R, Lemus H,Alvarez MT, Guiscafré JP et al. III. Etiología y cuadro clínico de los casos estudiados. 1988;19:361-370. 31. Muñoz 0 , Guiscafré $H$, Bronfman M, Gutiérrez G. IV. Características del tratamiento prescrito por los médicos familiares y los pacientes. Arch Invest Med Mex 1988;19:371-384.

32. Gutiérrez G, Guiscafré H, G onzález S, Bustamante E,Alvarez T, Muñoz 0 V. Evaluación de un esquema terapéutico basado exclusivamente en datos clínicos. Arch Invest Med Mex 1988;19:385-394.

33. Guiscafré H, Muñoz O, Padilla G, Reyes RM, González E, Bronfman M et al.VI Evaluación de una estrategia dirigida a los médicos familiares para incrementar el uso de la hidratación oral y disminuir el de antimicrobianos y dietas restrictivas. Arch Invest Med Mex 1988;19:395-408.

34. Martínez C, Guiscafré $H$, Muñoz 0 , G utiérrez G.VII.A nálisis del cumplimiento del tratamiento con los esquemas terapéuticos utilizados. Arch Invest Med Mex 1988;19:409-418.

35. Biller JA, King S,Rosenthal A, G rand RJ. Efficacy of lactase-treated milk for lactose-intolerant pediatric patients. J Pediatr 1987;111:91-94. 36.A serkkoff B, Bennet JV. Effect of antibiotic therapy in acute salmonellosis in the fecal excretion of Salmonellae. N Engl J Med 1969;281:636-640. 